\title{
A REPRESENTAÇÃO FEMININA NEGRA EM AMERICANAH, DE CHIMAMANDA NGOZI ADICHIE - IMAGENS CONTROLADORAS E OLHAR OPOSICIONAL
}

\author{
THE FEMALE BLACK REPRESENTATION IN AMERICANAH, BY \\ CHIMAMANDA NGOZI ADICHIE - CONTROLLING IMAGES AND \\ OPPOSITIONAL GAZE
}

\author{
Marília Carolina de Moraes Florindo ${ }^{1}$
}

Recebido em: 14 set. 2020

Aceito em: 10 nov. 2020

DOI: 10.26512/aguaviva.v5i2.34093

RESUMO: O presente artigo busca analisar a representação negra feminina na obra Americanah, de Chimamanda Ngozi Adichie. Publicado em 2013, o romance de Adichie conta a história de Ifemelu, uma jovem nigeriana que vai morar nos Estados Unidos. Ifemelu se depara com uma série de diferenças entre a Nigéria e os Estados Unidos, entre elas a imagem da mulher negra neste país. A personagem se dá conta de que existem diversas imagens controladoras termo utilizado por Patricia Hill Collins (2019) - da mulher negra no imaginário dos Estados Unidos. Assim, Ifemelu passa a escrever em um blog a respeito de suas experiências e reflexões sobre o que é ser negra e africana naquele país. O ato de escrever configura parte da aquisição do olhar oposicional da personagem, conceito de Bell Hooks, que significa o olhar crítico e questionador perante os modelos de feminilidade que são impostos em segmentos da arte e da vida cotidiana de mulheres negras. Portanto, ao abordar o enredo do romance, este artigo pretende, além de ressaltar a importância de obras como a de Adichie, que têm como protagonistas mulheres negras, apontar imagens controladoras, demonstrar a variedade de possibilidades de modelos de feminilidade e estudar a aquisição do olhar oposicional como forma de resistência a padrões impostos por uma sociedade racista, machista e limitada em suas visões sobre o que é ser mulher.

Palavras-chave: Representação feminina negra. Imagens controladoras. Olhar oposicional. Modelos de feminilidade.

ABSTRACT: This article aims to analyze the black female representation on the book Americanah, by Chimamanda Ngozi Adichie. Published in 2013, Adichie's novel tells us the story of Ifemelu, a Nigerian girl who leaves her hometown to live in the United States of America. Ifemelu faces a succession of differences and similarities between Nigeria and the

\footnotetext{
${ }^{1}$ Editora de Publicações na Editora Universidade de Brasília - UnB. Bacharel em Letras - Tradução: Inglês pela Universidade de Brasília (2010) e licenciada em Letras - Inglês pela Universidade Católica de Brasília (2017). Mestranda em Literatura pela Universidade de Brasília, na linha de Representação na Literatura Contemporânea. Eixo de interesse: gênero, raça e estudos pós-coloniais. E-mail: mariliapj@ gmail.com
} 
United States, among them the image of black women in the USA. The character realizes the existence of diverse controlling images - expression used by Patricia Hill Collins (2000) - of black women on the imaginary culture of the United States. Hence, Ifemelu starts writing a blog about her experiences and reflections on being an African black woman in that country. The sole act of writing partially sets up the acquisition of an oppositional gaze, concept coined by Bell Hooks, which means a critical and questioning gaze to femininity models imposed on art segments and on daily lives of black women. Thus, approaching the plot of the novel, this article, besides highlighting the importance of works like Adichie's, which present black women as protagonists, intends to point out controlling images, to demonstrate the variety of femininity models and its possibilities, and to study the acquisition of the oppositional gaze as a form of resistance to patterns imposed by a racist and sexist society, limited on its views of what does it mean to be a woman.

Keywords: Black female representation. Controlling images. Oppositional gaze. Femininity models.

\section{INTRODUÇÃO}

"Ninguém nasce mulher: torna-se mulher". A famosa citação de Simone de Beauvoir na abertura do segundo volume de sua obra O Segundo Sexo (1949) é uma forma de reflexão válida para o início da análise a que se propõe este artigo. Para "ser mulher" não basta apenas nascer com o sexo biológico feminino: é preciso se encaixar em uma variedade de padrões para que o "feminino" seja reconhecível ao olhar da sociedade. Para ser reconhecida enquanto uma mulher negra, a exigência é ainda maior. São necessários outros padrões, além daqueles gerais estabelecidos para as mulheres brancas. Sojourner Truth, em 1851, já se perguntava: se não me encaixo nos padrões, não sou uma mulher?

Para tentar responder a essa questão, recorreremos a algumas teóricas negras, como Patricia Hill Collins, que, em Pensamento Feminista Negro explicou o que são imagens controladoras, e o porquê de serem utilizadas: "Retratar as afro-americanas com os estereótipos da mammy, da matriarca, da mãe dependente do Estado e da gostosa ajuda a justificar sua opressão" (COLLINS, 20019, p. 135). Há um propósito no controle de imagens femininas, principalmente das mulheres negras, que é o de perpetuar as exclusões, limitando o espaço a ser ocupado por essas mulheres. Nos Estados Unidos, essas imagens são parte do imaginário da sociedade, devido aos quase duzentos anos de escravização de africanos e de um pós-abolição repleto de injustiças, falta de reparações e de condições para que a população negra se integrasse enquanto portadores de todos os direitos humanos. 
Em Americanah (2014), romance de Chimamanda Ngozi Adichie, vemos uma protagonista africana tentando se encaixar na sociedade estadunidense, entre os anos 1990 e 2000. A percepção dessas imagens controladoras, além daquelas que ela já carrega de sua criação, confronta a personagem, e ela se vê obrigada a resistir, a questionar, para se manter fiel a si mesma. Seu modo de confrontação é a escrita, local em que ela pode desenvolver seu olhar oposicional - o olhar que Bell Hooks define como o olhar questionador, que não aceita mais as representações que lhe são impostas.

Dessa forma, serão apresentados pontos da obra em que se pode observar o confronto com imagens controladoras e o desenvolvimento do olhar oposicional da personagem perante as representações da mulher negra com as quais ela se depara.

\section{Enredo e Representações observadas}

Ao longo da obra, podemos verificar que a personagem principal já tem a percepção de que determinadas representações do "feminino" são opressoras, como demonstra o seguinte trecho, quando Ifemelu percebe que sua performance de feminilidade passa por seguir determinados padrões de beleza, especialmente aqueles relacionados ao cabelo:

Ifemelu tinha crescido à sombra do cabelo de sua mãe. [...] Durante toda a infância, Ifemelu muitas vezes olhava no espelho e puxava seu cabelo, esticava os cachinhos, desejando que ficasse como o da mãe; mas ele permaneceu crespo e crescia com relutância; as cabeleireiras que o trançavam diziam que os fios cortavam que nem faca (ADICHIE, 2014, p. 49).

Contudo, Ifemelu já mostra uma predisposição ao questionamento quando não performa determinadas atitudes consideradas desejáveis para mulheres. Quando ouve a descrição que um colega faz dela, fica orgulhosa por ser diferente:

\footnotetext{
“Então, o que foi que Kayode disse sobre mim?” [...]

"Ele disse: 'Ifemelu é linda, mas dá trabalho demais. Sabe discutir. Sabe falar. Nunca concorda com ninguém. Mas Ginika é um doce de menina'." [...] Gostava dessa imagem de si mesma como sendo alguém que dava trabalho, que era diferente, e às vezes encarava aquilo como uma carapaça que a mantinha segura (ADICHIE, 2014, p. 69).
}

Observamos que o modelo de feminilidade desejável nesse contexto, ou seja, ser "um doce de menina", é não discutir, não falar, não discordar de ninguém. Esse e outros modelos 
são essenciais para a formação da personagem, mesmo quando servem de contraponto ao que ela é. Outros exemplos são a mãe e a tia de Ifemelu. Elas são mulheres importantes na trajetória da personagem, exercem influência, mas não são modelos absolutos. A mãe expressa o excesso de religiosidade e a renúncia total à vaidade quando decide cortar seus cabelos em nome da religião. A tia expressa um modelo muito comum na Nigéria, conforme explica a autora: o da mulher que se anula para viver relacionamentos marcados pela dependência financeira e emocional.

\begin{abstract}
Existem muitas jovens em Lagos com Fontes Desconhecidas de Riqueza. Elas vivem uma vida pela qual não podem pagar. Só viajaram para a Europa de classe executiva, mas têm um emprego cujo salário não paga nem uma passagem de classe econômica. [...] Temo que vá acabar como muitas mulheres de Lagos que definem sua vida pelos homens que jamais poderão realmente ter, tolhidas por sua cultura de dependência, com desespero nos olhos e bolsas de marca nos braços (ADICHIE, 2014, p. 454-455).
\end{abstract}

A respeito de sua tia, a percepção de Ifemelu das imagens controladoras estadunidenses começam a partir dela, que chegou antes aos Estados Unidos. Ela percebe o quanto a tia abre mão de sua personalidade para se encaixar nos modelos impostos pela sociedade estadunidense e esse é o início de uma série de anulações que Ifemelu observa ou às quais precisa se submeter para, mais tarde, poder libertar-se, quando se dá conta de que está sendo subjugada por uma cultura machista e, acima de tudo, racista:

E Ifemelu pensou, olhando para ela, que a velha tia Uju jamais usaria tranças tão malfeitas. Jamais teria tolerado os pelinhos encravados que pareciam passas em seu queixo, ou usado calças que sobravam entre as pernas. A América a deixara submissa (ADICHIE, 2014, p. 121).

\title{
2.1 Imagens Controladoras
}

Americanah (2014), já em seu início, apresenta uma das formas mais controladoras da imagem feminina negra: os cabelos. A cena inicial do livro é a personagem principal em direção a um salão de beleza. Este tema perpassa toda a obra e acompanha o crescimento da personagem, demonstrando o sofrimento pela emancipação e a luta pela aceitação, por si própria e pela sociedade, de sua imagem.

Collins dá diversos exemplos de como funcionam as imagens controladoras sobre a aparência da mulher negra nos Estados Unidos. Um deles segue no seguinte trecho: 
Em Color, um curta-metragem que aborda o impacto da cor da pele na vida das mulheres negras, a mãe da personagem de pele escura tenta fazer com que a filha fique imóvel para passar o pente quente e pergunta: "Você não quer que seu cabelo balance que nem o da sua amiga Rebecca?". Vemos a tristeza da menina negra sentada na cozinha, protegendo as orelhas para que não se queimem com o pente quente que vai alisar seu cabelo. A mãe não consegue deixá-la bonita, mas apenas "apresentável” para a igreja (COLLINS, 2019, p. 169-170).

Para Ifemelu, há a sombra dos cabelos da mãe, somada à pressão para se enquadrar no padrão de beleza estadunidense. Um trecho que marca bem essa angústia é quando a personagem precisa se submeter a um procedimento químico para ter chances de conseguir um emprego:

\begin{abstract}
Meu cabelo cheio e incrível ia dar certo se eu estivesse fazendo uma entrevista para ser backing vocal numa banda de jazz, mas preciso parecer profissional nessa entrevista, e profissional quer dizer liso, mas se for encaracolado, que seja um cabelo encaracolado de gente branca, cachos suaves ou, na pior das hipóteses, cachinhos espirais, mas nunca crespo (ADICHIE, 2014, p. 222).
\end{abstract}

Ifemelu percebe que está se enquadrando nas imagens controladoras que a sociedade racista impõe. Embora ela não se mobilize imediatamente nesse sentido, há uma busca por libertação, de retorno às suas origens e à sua naturalidade. Ela precisava de seus cabelos naturais, precisava se aceitar como realmente era, num processo que não é livre de angústia, questionamentos e dor. Sua amiga Wambui a aconselha nesse sentido: "Relaxar o cabelo é que nem ser preso. Você fica numa jaula. Seu cabelo manda em você. [...] Está sempre lutando para fazer seu cabelo ficar de um jeito que não é o normal dele” (ADICHIE, 2014, p. 226).

A importância dessa representação de busca por libertação de imagens controladoras na obra é notável. É parte de um processo desmistificador de padrões de beleza, e de valorização da beleza negra. É uma resposta efetiva às demandas atuais das mulheres, principalmente as mulheres negras, que há muito questionam as pobres e limitantes representações de si mesmas na arte, que em nada correspondem à realidade. Ifemelu percorre um caminho muito árduo, mas que muitas mulheres também já percorreram, e aquelas que ainda não passaram pelo processo de libertação de imagens controladoras podem se sentir inclinadas e inspiradas por essa representação de um modelo de feminilidade diferente dos que já existem no imaginário da sociedade. 


\subsection{O Olhar Oposicional}

É no âmbito dessa demanda social por representações mais justas que falaremos sobre o desenvolvimento do olhar oposicional. Toda a trajetória da personagem a leva para a aquisição e o refinamento desse olhar, um olhar de contestação sobre o que era vendido a ela como modelo único de comportamento e aparência.

Bell Hooks trata do olhar oposicional como "olhar de uma certa maneira, para que se possa resistir" (2017, p. 485). Por muito tempo, as mulheres negras foram confinadas a representações que reforçavam preconceitos e as impediam de enxergar possibilidades diferentes em suas vidas. Questionar essas representações, portanto, tornou-se crucial para resistir, ou seja, negar que essas representações sejam a verdade sobre suas próprias personalidades e vivências.

Ifemelu, enquanto mulher negra e africana, já nasceu em um ambiente que a faz questionar o mundo e a si mesma. Ela enfrenta diversos problemas devido a representações falhas de si e ao controle de imagens sobre o que ela poderia se tornar. Contudo, ela desenvolve seu olhar crítico para essas representações, um olhar oposicional, que contesta as estruturas vigentes. Dessa forma, ela se vê capaz de criar sua própria voz e decidir seus próprios caminhos.

A forma como Adichie escolhe como representação do lugar de contestação, que é a escrita, é emblemática. Por meio da escrita, tanto Ifemelu quanto a autora questionam e oferecem novos olhares à uma sociedade viciada em uma forma única de olhar a história de mulheres negras. $\mathrm{O}$ ato de escrever torna-se poderoso para Ifemelu, e proporciona à personagem uma carreira como escritora. Há a subversão da representação inicial, em que a personagem apenas via a perspectiva de trabalhar em subempregos, quando enfrentou imensas dificuldades até encontrar um emprego minimamente digno, que permitisse a ela uma vida decente nos Estados Unidos.

Aqui, o simbolismo da importância do olhar oposicional é o de possibilidade de que essa contestação e esses questionamentos sejam ouvidos a ponto de mudar a vida da personagem. É um encorajamento para que não se aceite mais que a própria vida seja limitada pelo racismo, machismo, ou qualquer outra forma de exclusão.

\section{Considerações Finais}

O presente artigo buscou examinar a obra de Adichie como uma forma de representação feminina negra que desafiasse alguns padrões vigentes na sociedade. Nota-se que a obra 
ficcional trata de questões muito observáveis na realidade, o que aproxima a leitora de sua própria experiência. A vida da personagem passa por uma grande mudança quando ela chega nos Estados Unidos, e assim ela também precisa mudar e amadurecer para encarar os desafios impostos, como são as imagens controladoras de sua existência enquanto mulher e enquanto negra. A personagem e toda a obra acabam por cumprir um papel social de demonstrar diferentes representações que propiciem às mulheres negras uma diversidade maior de possibilidades de olhares sobre suas vidas na arte.

Para além das questões ficcionais da obra, o próprio fato de Americanah (2014) ser escrito por uma autora negra, nigeriana, e ter como personagem principal uma mulher negra já é um grande passo para os modelos de representações femininas negras com os quais nos deparamos. Quando Hooks fala em seu artigo que "Fazemos mais do que resistir. Criamos textos alternativos que não são meramente reações" (HOOKS, 2017, p. 504), um desses textos alternativos é a própria existência de uma autora negra bem-sucedida, que escreve sobre mulheres negras bem-sucedidas. São essas representações imagéticas da arte e do cotidiano que criam possibilidades diferentes para as mulheres negras, e mostram que não há limites para o que se chama de "feminino" e "modelos de feminilidade".

\section{REFERÊNCIAS}

ADICHIE, Chimamanda Ngozi. Americanah. Tradução Julia Romeu. $1^{\text {a }}$ ed. São Paulo: Companhia das Letras, 2014.

BEAUVOIR, Simone de. O Segundo Sexo: a experiência vivida, volume 2. Tradução Sérgio Milliet. 3. ed. Rio de Janeiro: Nova Fronteira, 2016.

COLLINS, Patricia Hill. Pensamento feminista negro: conhecimento, consciência e a política do empoderamento. Tradução Jamille Pinheiro Dias. 1. ed. São Paulo: Boitempo, 2019.

HOOKS, Bell. O Olhar Oposicional: Espectadoras Negras. Tradução Raquel D’Elboux Couto Nunes. In: Traduções da Cultura: Perspectivas Críticas Feministas (1970-2010). BRANDÃO, Izabel. [et al] (org.). p. 483-509. Florianópolis: EDUFAL; Editora da UFSC, 2017.

TRUTH, Sojourner. Ain't I a Woman? In: CONVENÇÃO DOS DIREITOS DAS MULHERES, Akron, Ohio, 1851. [comunicação oral] 